3-1-2021

Transfusion-associated circulatory overload (TACO): Significance of appropriate pre-transfusion risk assessment to prevent fatal health outcomes

Nazish Sana

Muhammad Shariq Shaikh

Follow this and additional works at: https://ecommons.aku.edu/pakistan_fhs_mc_pathol_microbiol

Part of the Pathology Commons, and the Pulmonology Commons 


\title{
Transfusion-associated circulatory overload (TACO): Significance of appropriate pre-transfusion risk assessment to prevent fatal health outcomes
}

\author{
Nazish Sana, Muhammad Shariq Shaikh
}

Madam, Transfusion of blood products is a life rescuing medical intermediation; however, associated adverse transfusion reactions are major pitfalls. Transfusionassociated circulatory overload (TACO) is life-threatening pulmonary oedema that develops secondary to volume overload. Underlying precipitating factors include ages $>60$ years or $<3$ years, low body mass index (BMI), rapid transfusion rate and pre-existing volume overload conditions such as heart disease, renal failure, lung disease or low albumin levels. Sign and Symptoms include dyspnoea, tachypnoea, tachycardia, hypoxia, raised jugular venous pressure, broad pulse pressure and hypertension, that appears during or either six hours posttransfusion. ${ }^{1}$ TACO should be discriminated from transfusion-related acute lung injury (TRALI) by high jugular venous pressure, pulmonary arterial pressure to $>18 \mathrm{mmHg}$, hypertension, brain natriuretic peptide levels $(>1200 \mathrm{pg} / \mathrm{ml}$ ) and response to diuretics. Management of TACO includes immediate discontinuation of transfusion, diuretics, supplementary oxygen, and assisted ventilation if indicated. ${ }^{2}$

Serious Hazards of Transfusion (SHOT) in 2018 reported TACO as the most typical reason for transfusion-related deaths. Over the period of 11 years (2007-2018), overall cases raised from six to one hundred and ten, including the increase in mortality from one to five and one significant morbidity from three to thirty-six cases. ${ }^{3}$ Interestingly, timely and appropriate preventive actions can reduce this severe reaction to zero. A precise risk assessment before

Department of Pathology and Laboratory Medicine, Aga Khan University Hospital, Karachi, Pakistan..

Correspondence: Nazish Sana. e-mail: naxish.ahmer@gmail.com transfusion is recommended by SHOT for TACO elimination, especially if the patient has underlying risk factors. Preventive strategies in such predisposed patients include reviewing the need for transfusion, deferring the transfusion until issue can be resolved, transfuse according to body weight, measure fluid balance, consider prophylactic diuretic, slow transfusion rate and monitoring vital signs including oxygen saturation.

Thus, TACO is a serious but avoidable transfusion reaction. Appropriate assessment prior to transfusion in every patient is important to ensure safe blood transfusion practice.

Disclaimer: None.

Conflict of interest: None.

Funding sources: None

\section{References}

1. Menis M, Anderson SA, Forshee RA, McKean S, Johnson C, Holness $\mathrm{L}$, et al. Transfusion-associated circulatory overload (TACO) and potential risk factors among the inpatient US elderly as recorded in Medicare administrative databases during 2011. Vox Sang 2014;106:144-52. doi: 10.1111/vox.12070.

2. Semple JW, Rebetz J, Kapur R. Transfusion-associated circulatory overload and transfusion-related acute lung injury. Blood 2019;133:1840-53. doi: 10.1182/blood-2018-10-860809.

3. Grey S, Bolton-Maggs P. Transfusion-Associated Circulatory Overload (TACO) $n=110$ : Annual Shot Report 2018. [Online] 2018 [Cited 2021 February 14]. Available from URL: https://www.shotuk.org/wp-content/uploads/myimages/17b.-Transfusion-Associated-CirculatoryOverload-TACO.pdf

https://doi.org/10.47391/JPMA.04-532 